\title{
SOLAR ENERGY SYSTEMS IN THE RECONSTRUCTION OF HERITAGE HISTORICAL BUILDINGS OF THE NORTHERN TOWNS (FOR EXAMPLE SAINT-PETERSBURG)
}

\author{
Vera Murgul* \\ Saint-Petersburg State Polytechnical University, Saint-Petersburg, Russia
}

The use of solar energy supply systems for the reconstruction of facilities, historical and cultural monuments, faces many difficulties. Particularly because of the need to preserve the outside shape of the building. It is necessary to find a method of integration of solar energy system supply, but not at the expense of the architectural heritage, and ensuring optimum production of solar energy. The method should not touch at all the façade of the architecture. The author proposes to allocate additional energy supply systems based on solar energy in the class of temporary structures, potentially separable from the capital base of the building. Hence, the creation of the concept of Building-independent temporary photovoltaics constructions (BITPVC). This article is dedicated to the issues of architectural adaptation and harmonious integration of solar energy technologies in the historic environment of the northern towns (for example Saint-Petersburg).

Key words: Solar power, Photovoltaic systems, Heritage historical buildings, Energy efficiency, Reconstruction, Restoration

\section{INTRODUCTION}

The influence of the elements of solar systems to the architecture of buildings is undeniable. From the seventies of the twentieth century, lots of terms and definitions appeared, trying to describe a style of architecture based on the principles of taking into account the climatic conditions and the exploitation of the potential of local energy resources such as solar energy [13].

This is the very first serious approach to the architecture, as a science, indicating a significant impact of the overall ecological stability, in connection with ubiquitous knowledge of the necessity for environmental protection, reduction of technogenic and anthropogenic pressure on the biosphere.The energy crisis of the twentieth century brought a certain contribution in the form of a new architectural style, as well as the desire to achieve energy independence for countries which lost their reserves of traditional energy resources $[05,08,11]$.

The history of architecture, in a certain sense, is the process of aesthetic conquest of new technical means, used in civil engineering, "Conversion of utility to elegance", in the words of A. K. Krasovsky. Theory of Architecture usually focuses on the mutual relation between building constructions and architectural forms. But, in the process of architectural forms design, the elements that are not directly related to the structural base of the building, are included too. Sustainable ways of heating, ventilation, water supply and so on, directly or indirectly affect the architectural planning. In other words, the whole gamut of technical means used in the construction industry, in one way or another affect the process of the forms' design in architecture. The progress of contemporary architecture consists not only of the implementation of innovative constructions solutions, but also the implementation of the latest facility for the objects support, which in turn affect forms' design. One of the important factors that affect the shape of the modern building is the elements associated with the use of solar energy. When it comes to reconstruction of historical buildings, the architectural design of the elements for engineering support is a particular task. [07] Analysis of the current experience of energy efficient modernization of buildings, monuments of history and culture, based on solar energy has shown the existence of principally different approaches [04, 12, 14]. 
The development level of PV technology, these days, allows us to incorporate solar technology into buildings transparently. A conflict situation between the need of preserving the outward form of the building and maintaining solar energy production can be avoided by using solar modules (BIPV) integrated on building facades and window elements [02, 09, 15, 16]. Figure 1 demonstrates an example of energyefficient modernization of the churches in Germany, with the application of Building-integrated photovoltaic (BIPV) technology.
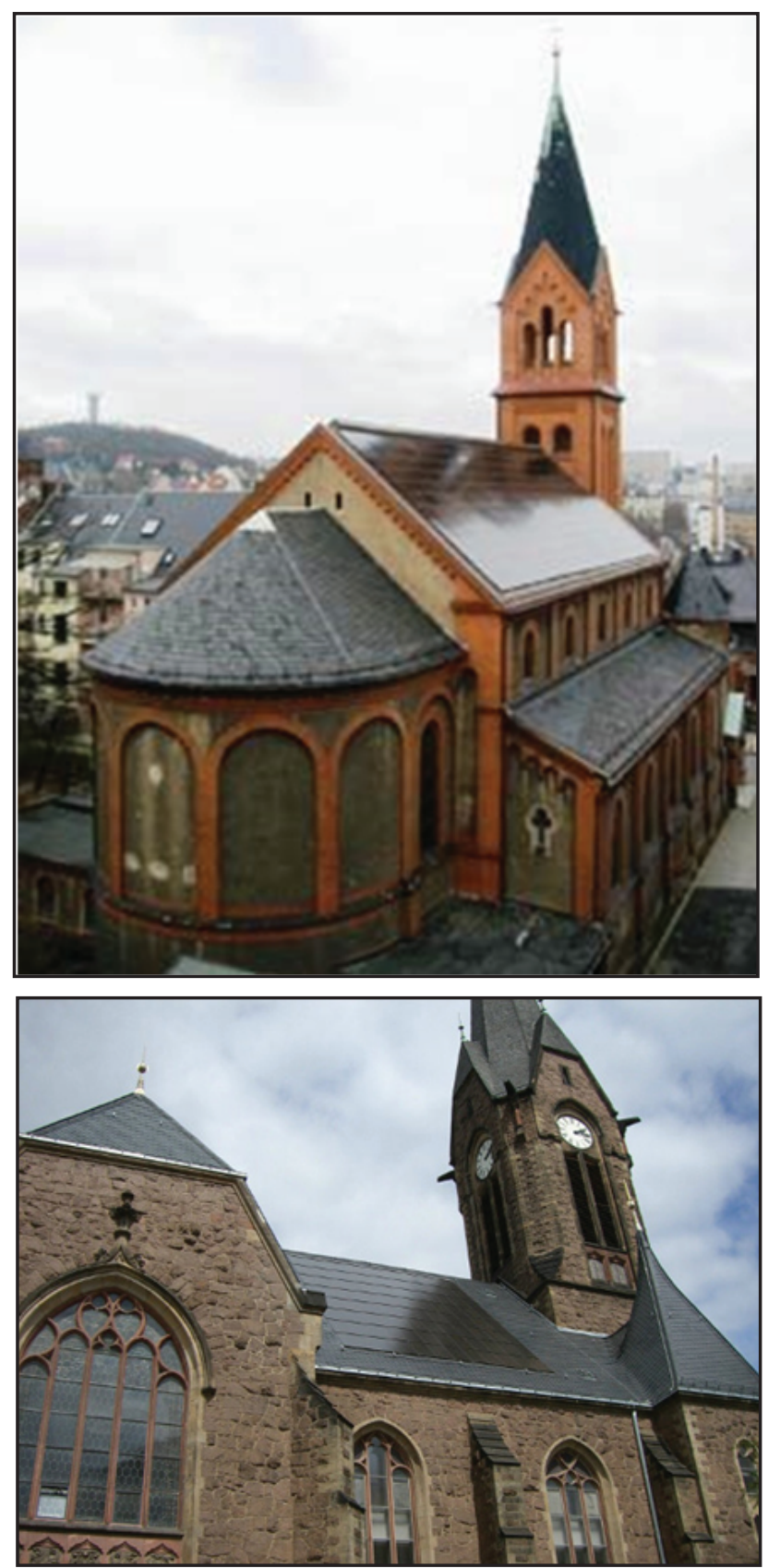

Figure1: Herz-Jesu-KircheinPlauen, photovoltaic systems on the roof of the Lutheran Church in Saxony
In most cases, the interests of protecting cultural heritage sites are placed above all. Technological upgrading of external elements of the structure in order to produce additional energy is subordinate, the integration of the equipment into the external elements of the structure is done transparently.

However, there are great examples of "ideologically active" energy modernization of buildings. Contemporary energy modernization of unique objects - monuments, often carries the goal, not only the transition to energy supply based on renewable sources, but the idea of the declaration of principles of the new energy policy, new insights into the process of production and consumption of the energy. One of the first major projects in this area was the project of reconstructing the Reichstag building - a monument of world importance. (Figure 2)
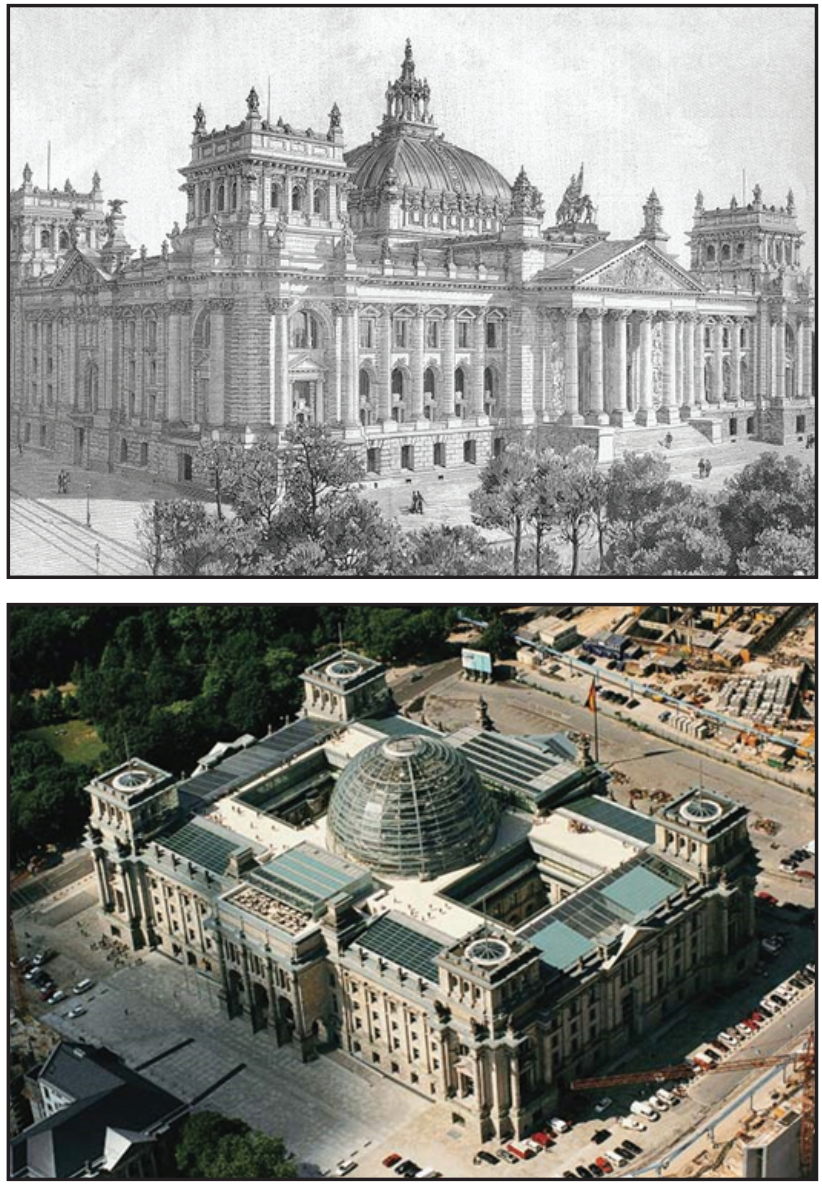

Figure 2: Reichstag building. Photo from 1894 and contemporary look

This architectural monument of world importance had significant external changes. This is an example of a facility getting a new, but at the same time still recognizable, role - the expression of the dominant ideology, which is not the policy of the 
German state, but the policy of global energy consumption.

Raised dome and roof covering are used for the production of heat and electrical solar energy. Stairs and viewing platforms inside the dome are used to demonstrate to visitors the production of solar energy.

Reconstruction of this monument of world importance was created not because of power shortages in Berlin. Reichstag has always been and remains a symbol of German statehood, and now it carries the idea of a new European energy policy.

Summarizing the existing international experience in the reconstruction of objects based on the use of solar energy, we can single out two basic approaches:

- «style design», where the elements of the solar energy supply, are set to a facade and they dominate in the renewed appearance;

- «camouflage», where we're using the principle of minimal intervention in the original appearance of the building.

This study is dedicated to the issues of architectural adaptation and the harmonious inclusion ofsolarenergytechnologies in the historic neighborhood of a northern city (for example Saint-Petersburg). Also, it is necessary to ensure the efficient production of solar energy in the climatic conditions of the North-Western region of Russia.

\section{METHOD, RESULTS}

\section{Determining the actual production of solar energy in the North-West climatic conditions}

The subject of this research - the historic building St. Petersburg. The use of solar energy is considered one of the components of the energy efficiency concept. Independently of reconstructing the object, climatic resources of the region will determine the efficiency and even the appropriateness for the production of electricity based on solar radiation.

When there is data regarding energy efficiency (electricity generation), solar photovoltaic (PV) modules, and electricity supply systems then is possible to have a solution for the question regarding the appropriateness of the application of solar technology.

The amount of electricity generated by photovoltaic modules (PVM), is directly dependent on the amount of solar radiation in these climatic conditions and is given by the formula: $W_{\ni \jmath}^{\Phi \ni M}=\int_{t_{1}}^{t_{2}} E_{i}^{C И} \cdot \eta^{\Phi \ni M} \cdot S^{\Phi \ni M} \cdot d t$

Where $E_{i}^{c n}$ - the density of the flow of the solar radiation on the work surface modules, according to their orientation in space and a time; $\eta^{\Phi \ni M}$ - the efficiency of the solar module, depending on the technology process, stated by the manufacturer;

$\mathrm{S}^{\Phi \ni \mathrm{M}}$ - The area of photovoltaic module in accordance with its specifications;

and $t_{1}$ and $t_{2}$ determine the time period for the calculation of generated electricity.

To determine the effectiveness and appropriateness of implementing photovoltaic modules and systems of energy supply to their base, it is necessary to first determine the amount of solar radiation oriented on the surface of modules under real climatic conditions.

Calculations [01] gave the following results.

Integral power values of the solar radiation flow hitting the south-oriented surface per month are shown in the Figure 3.

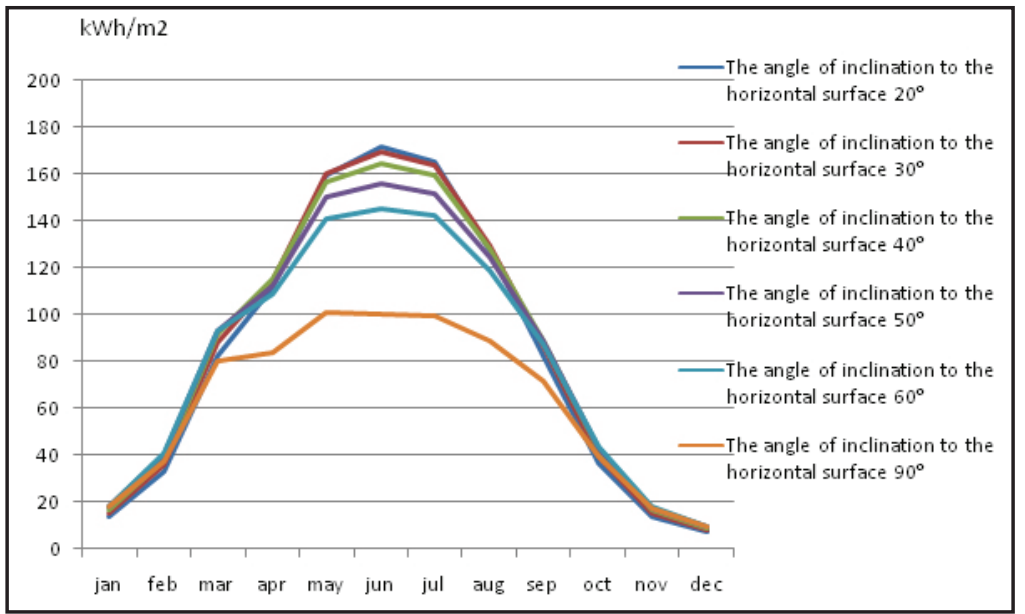

Figure 3. SR power input in reference to the south-oriented surface, $\mathrm{kWh} / \mathrm{m}^{2}$ 


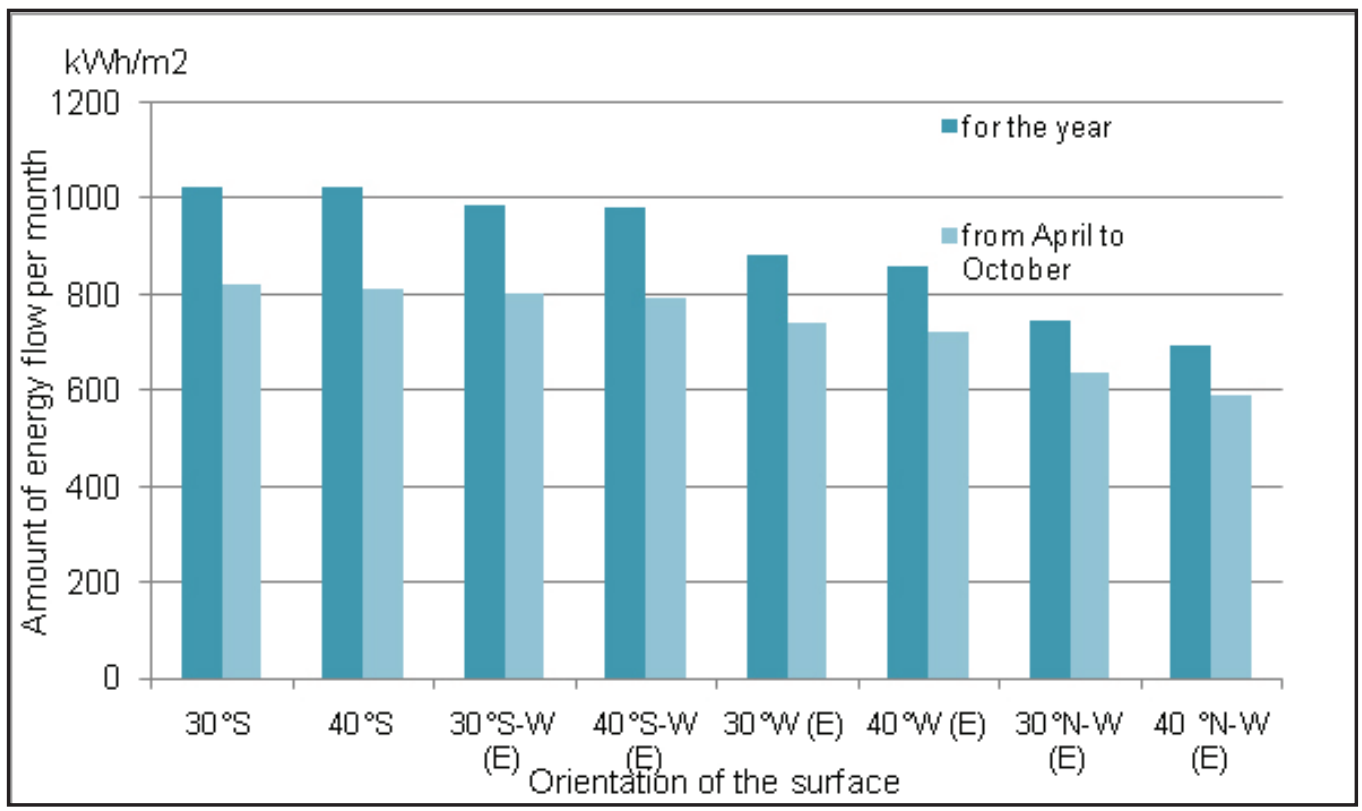

Figure 4: Amount of solar energy flow per month for the year and from April to October

By this we practically see an absence, or a significant loss of solar energy in the winter time. It tells us about the feasibility of a seasonal exploitation of solar energy supply system.

\section{DISCUSSION}

Analysis of the protective regulations of SaintPetersburg showed the following:

In Saint-Petersburg is a specific combination of protecting facilities, environmental protection and urban planning protective practices. General city silhouette, squares and prospects of the streets of the historic center are the subject of protection, along with certain objects of cultural heritage.

Summarizing the main provisions of security regulations for historic buildings of St. Petersburg, we can draw the following conclusions:

- in most cases, changes in exterior facades are not allowed. The only exception is the level of the first floor. Also, it is impossible to change the configuration of exterior slope of the roof.

- in most cases overlap of courtyard spaces and changing of courtyard facades are allowed, including a change of slope of the courtyard roofs. Thus, in terms of operating in St. Petersburg standards for protection of historic buildings, the opportunities to insert solar convertors to the external elements of building construction are very limited.
Significant losses can occur in the shade. St. Petersburg characterized excessive density of urban development, as well as perimeter construction sites, where building wings form internal courtyards. As a result, against the background of an already weak solar radiation, there is still significant losses from shade at the location of the photovoltaic modules on courtyard facades and slopes of the courtyard roofs. Whereby the backyard wings are usually lower than the street ones.

Given all the above, the author proposes to provide additional energy supply systems based on solar energy in the class of temporary structures, which will be potentially separable from the capital core of the building. We introduce the concept of time transforming energy supply system $[06,07]$.

On the basis of multi-story steel construction, bearing the elements of solar heat and electrical energy, open and glazed terraces, galleries, passages on levels 1-2, and atriums can be created.

Glazed volumes can be used as passive solar heating systems with the inclusion of airconditioning and ventilation system of the building $[03,06]$.

Such a system can be partially or fully dismantled during the winter, or be transformed by increasing the glazing areas. During the summer, restoring elements of the system for production of solar energy and reducing the glazed areas should be done. 
As an example, we will consider covering the pedestrian area, courtyard expanse.

Construction is covering shopping areas and pedestrian streets known in the history of architecture and urban contemporary practice (Figure 5). A new round of technological development can give a new feature to the glazed structures' cover - the feature of energy supply (Figure 6).
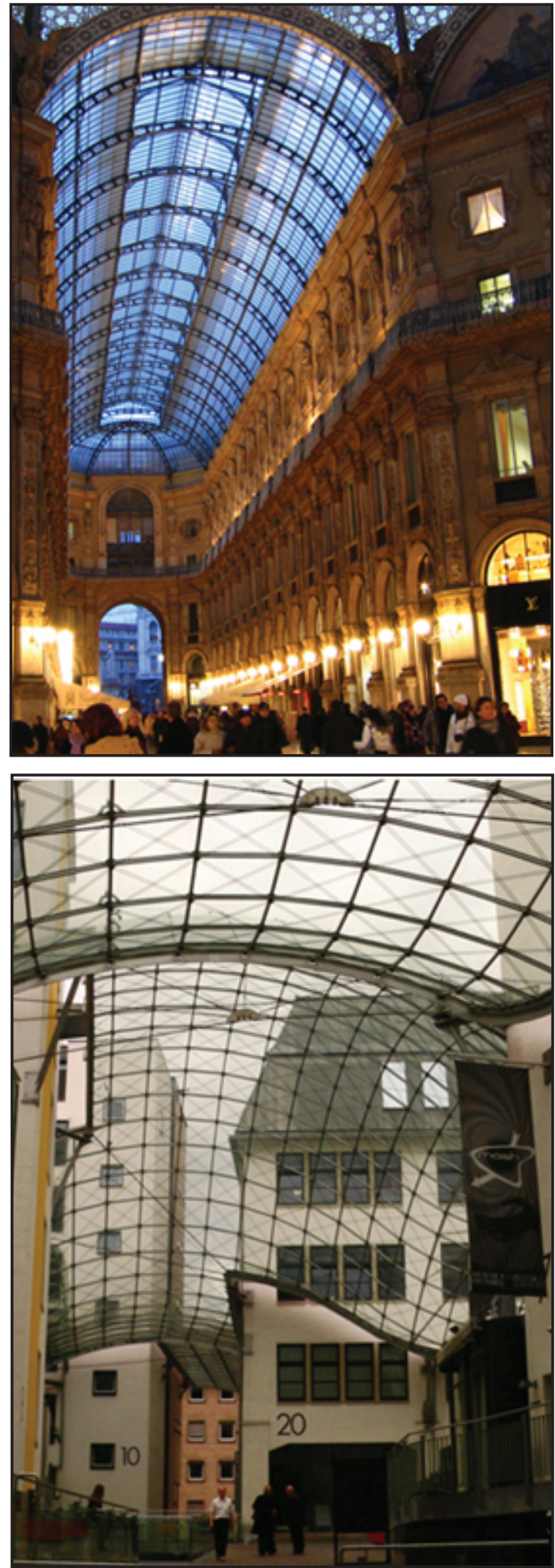

Figure 5. The Galleria Vittorio Emanuele II in Milan and pedestrian street in Darmstadt
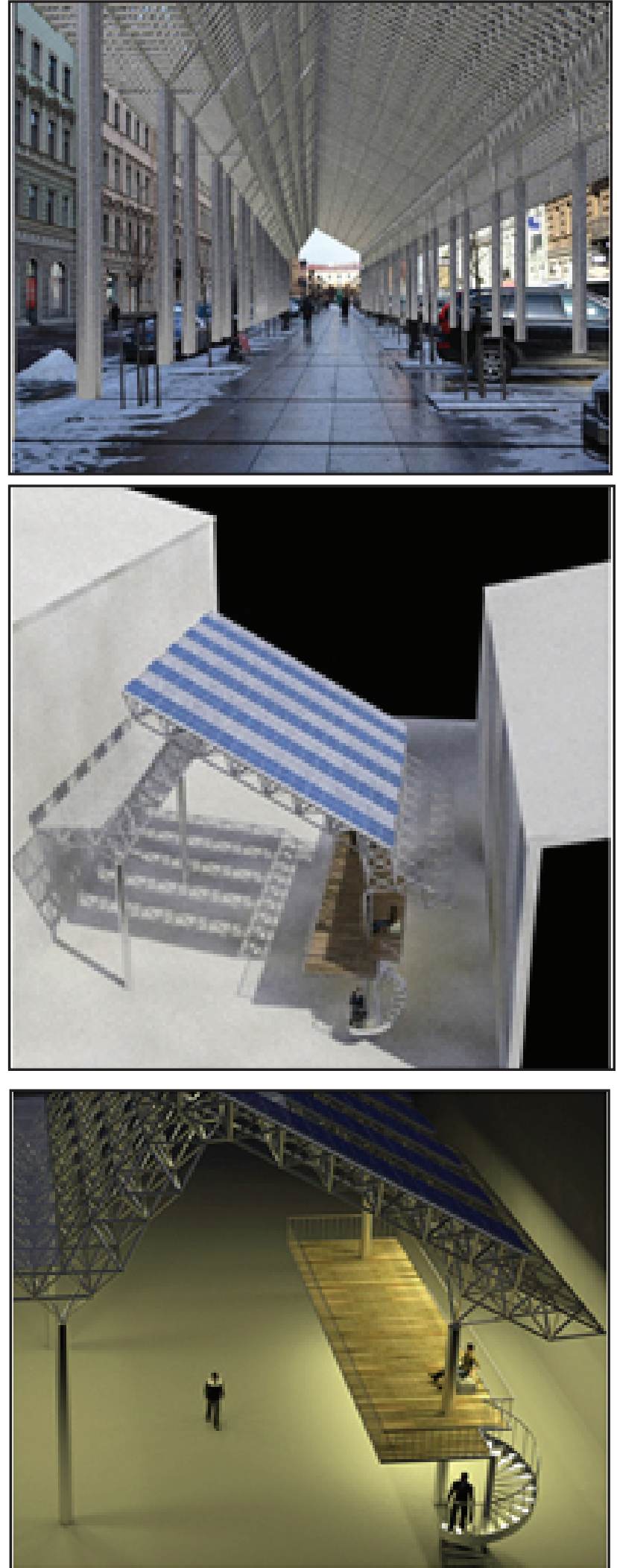

Figure 6: Model of temporary energy-supplying structure for the covering of the pedestrian zone

The construction's coverage of the courtyards can be temporary as well as permanent. But there is actually another seasonal variation they are more beneficial in the winter time. Tem- 
porary constructions of courtyard covering, raised on an experimental basis, afterwards could become permanent. The figure 7 and 8 shows the construction's coverage of the models, providing coverage of the courtyard space on the basis of PV-modules and lighting systems.

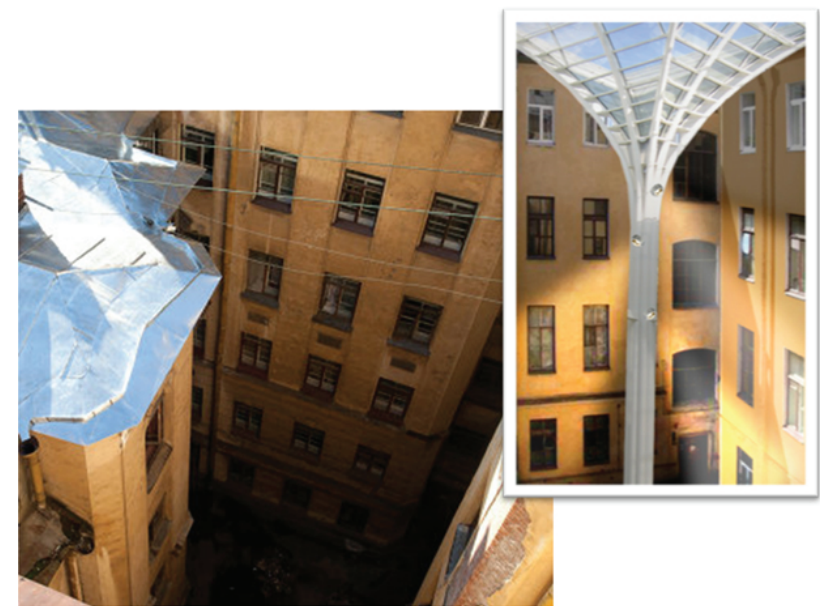

Figure 7:Model of temporary energy-supplying structure for providing coverage of the courtyard space on the basis of PV-modules and lighting systems

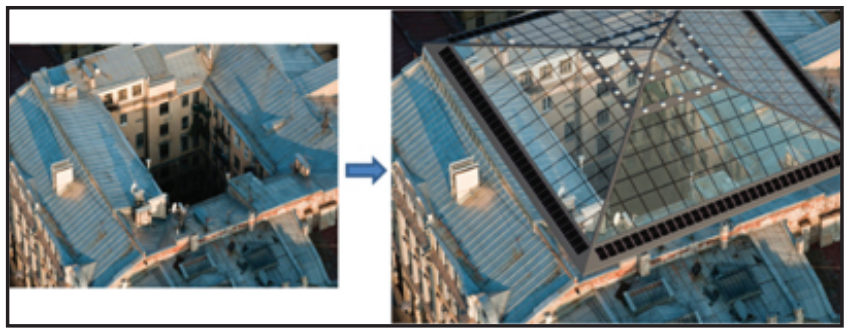

Figure 8: Model of temporary energy-supplying structure for providing coverage of the courtyard space on the basis of PV-modules and lighting systems

In the row of historic buildings, it can be applied by build on the empty land (gaps) (Figure 9). The construction's coverage of the models, providing coverage of the courtyard space on the basis of PV-modules and lighting systems.

Temporarily filling the gap's space with glass "inserted buildings" on the basis of mounting and transforming energy supplying structures, has a several potential advantages:

- production of electric and thermal energy based on solar energy;

- additional functional areas in the city center,

- opportunity at any time to revise the architectural decisions and, if necessary, return gaps to the original state, for its capital construction.

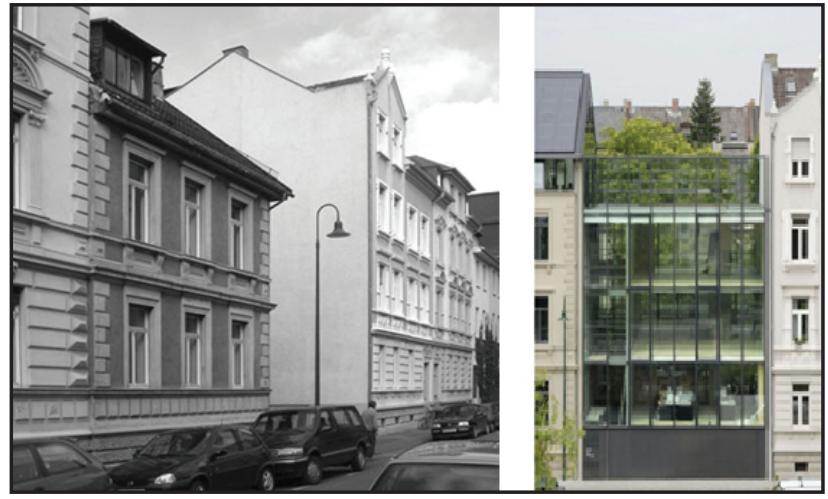

Figure 9: Possibility of using temporary energy-supplying systems in the buildings of empty lots.

Figure from [10]

Static architectural objects are traditionally focused on immutable, non-separable from the construction of the building envelope energy supply system.

Today, sustainable development of the environment no longer involves stable and consistent architecture, but variability as the main principle of conformity to dynamically changing conditions of society. Providing the mobility and flexibility to the energy supply system, will constitute a step towards the dynamic adaptation of the built environment to meet the changing demands of society.

The proposed energy supply system of the building can be updated much more frequently than would occur in cycles of the reconstruction of the architectural object. The modern pace of progress in the field of energy supply systems and air conditioning of buildings on the basis of solar energy over time commensurate with the life of the building between its renovations.

Summarizing the advantages of this approach, we can single out the following:

- demonstration of generating of "green" energy and commitment to the principles of sustainable development;

- possibility of seasonal exploitation (including seasonal fluctuations in solar radiation);

- creation of additional temporary spaces in the downtown;

- facade protection from the aggressive influence of environment.

- easiness of technical recovery;

- the possibility of a quick dismantling and return to the original state of the building without compromising capital construction; 
St. Petersburg strategy of preserving cultural heritage defines the main priorities, eligibility criteria and areas of protection by "conservation through development, development through conservation».

Accelerating the development of scientific technical progress, recognition of the reality of global climate change, the overall dynamics of social development entails changes in all spheres of human activity, including the architecture, and in particular in the energy supply, which is showing an impact on the architecture.

Currently, the architectural practice has developed the concept of "passive solar building design". In fact, it comes to managing heat flow by means of architectural design. Logic of architectural design comes from the formation and movement of heat fluxes. Architecture of the buildings, based on the principles of "passive design" can not fail to carry the national and regional features, and almost certainly will demonstrate the continuity of historical forms of national buildings.

Passive solar thermal systems use the principle of moving the heat through the system due to its natural gravity, which occurs with the density difference of the heated and cooled coolant. In fact, any building adjoined to the south (south-west, south-east) side of the glazed surfaces can operate as a passive solar heating system. However, the energy gain of the building from the adjoining glass surfaces is not great.

By deliberately placing translucent and opaque building elements, flows of solar radiation and heat fluxes are controlled in the building. For thermal energy storage use massive structural elements.It should be noted that the principles of the passive solar heating system is largely based on the most important modern concept of energy efficiency - the concept of "Passive House" («Passivhaus»).

Glass is a very "generous" material for work in the historic environment. Glass does not dominate the building visually, it is capable of reflecting clouds and green squares, it initially remains itself. Glazed metal and wooden structures are very simple, including installation and potentially collapsible, capable of carrying both temporary as well as permanent functions, and also serve for the restoration and preservation of historical and cultural monuments. The massive and pretentious facade, lightness and transparency of the glass - "the harmony in contrast", may become an interesting architectural solution.
Use of a thermal system for the buildings of reconstructed historic urban areas is problematic, in even a greater extent than the use of photovoltaic.

Indeed, whatever example we have discussed, glass ceilings are playing the role as a thermal solar system, or they are the focus of the facade, or basic architectural concept of the building. And when it comes to remodeling and restoration of historic buildings, "hiding" these systems is practically impossible.

And if the integration of solar thermal systems in the historic appearance of the building is extremely painful and difficult, it makes sense to initially abandon this idea and consider them as separate volumes, with their own basis of form design, which determine the energy efficiency of their properties.

Infinitely "adjusting", in principle, not very compatible systems, is complex to resolve and to the detriment both of them.

Use of thermal solar systems (glazed surfaces upgrade) to a greater extent than photovoltaic, inclines toward the principle of temporary mounting structures. Separation of the "latest" part will provide the opportunity to return to the historic appearance of the building at any time, and the original "integrity" of the attached volume will retain the logic of a passive solar system.

\section{CONCLUSION}

Thus, the present date classification of solar systems can be supplemented with another element: group Building-independent temporary photovoltaics constructions (BITPVC).

Photovoltaic systems can be divided into three categories in accordance with their position to a building, which is an energy recipient:

- Building attached photovoltaics systems (BAPV). Integrated into the building envelope system;

- Building-integrated photovoltaicssystems (BIPV), (subspecies which are

Building-integrated solar thermal systems (BIST) and Building-integrated hybrid systems (BIPVT))

- Building-independent temporary photovoltaics constructions (BITPVC)

Also worth noting is that the temporary energy supply structure can be saturated with PV-elements, and also with thermal and hybrid solar systems. 
Speaking of solar energy supply facilities, we can safely call the use of solar energy as form design factor in architecture. Harmonious integration of solar energy technologies in architecture of urban historic environment, a task of architectural adaptation, is important and relevant.

St. Petersburg is an integral part of Russia's cultural heritage. It is impossible to overestimate the value of a symbolic and ideological space. Demonstrative inclusion of solar energy generating systems in the urban environment can become a symbol of commitment to the principles of environmentally sound production and consumption of energy, the principles of sustainable development of society as a whole. However, when it comes to remodeling and restoration of historic buildings, transforming urban spaces of the historic center, the most important principle of the architect should be an understanding that absolute priority is preservation of cultural heritage.

\section{REFERENCES}

1) Aronova, E., Murgul, V. (2013): The evaluation of the appropriateness for using solar energy technologies in the historical building of Saint-Petersburg and the climatic conditions of the North-West region, Architecture and Modern Information Technologies, Vol. 2 (23), pp. 97-117;

2) Davidsson, H., Perers, B., Karlsson, B (2012): System analysis of a multifunctional $\mathrm{PV} / \mathrm{T}$ hybrid solar window, Solar Energy, Vol. 86 (3), pp 903-910;

3) Gabriyel, I., Ladener, Kh.,(2011) Rekonstruktsiyazdaniypostandartamenergoeffektivnogodoma, St. Petersburg: BKhV-Peterburg;

4) Moschella, A., Salemi, A., Lo Faro A, Sanfilippo, G., Detommaso, M., Privitera, A. (2013): Historic Buildings in Mediterranean Area and Solar Thermal Technologies: Architectural Integration vs Preservation Criteria, Energy Procedia, Vol. 42, Pp 416-425;

5) Murgul, V. (2014): Features of energy efficient upgrade of historic buildings (illustrated with the example of Saint-Petersburg), Journal of Applied Engineering Science, Vol. 12, № 1, pp 1-10;

6) Murgul, V. (2013): Solar energy in the reconstruction of urban environment of historic building Saint-Petersburg, Architecture and Modern Information Technologies, Vol. 2 (23), pp. 1-24;

7) Murgul, V. (2013): Capabilities of using the solar energy for energy supply of the dwelling buildings of the historical area of SaintPetersburg and for city environment quality improvement, Architecture and Modern Information Technologies, Vol. 1 (22), pp. 1-18;

8) Nemova, D., Murgul, V., Golik, A., Chizhov, E., Pukhkal, V., Vatin N.(2014): Reconstruction of administrative buildings of the 70s: the possibility of energy modernization, Journal of Applied Engineering Science, Vol. 12, № 1, pp 37-44;

9) Norton, B., Eames, P.C., Mallick, T.K., Huang, M.J., McCormack, S.J (2011): Enhancing the performance of building integrated photovoltaics, Solar Energy, Vol 85, pp. 1629-1664;

10) http://www.opus-architekten.de/inhalt/opusArchitekten.htm, retrieved on January 8th, 2014;

11) Pavlicic, N., Perazic, M., Djuric-Jocic, D., Knezevic, M., (2014): Engineering education in the field of civil engineering, Journal of Applied Engineering Science, Vol. 12, № 1, pp 11-18;

12) Polo López C. S., Frontini, F. (2014): Energy efficiency and renewable solar energy integration in heritage historic buildings, Energy Procedia Vol. 48 pp. 1493 - 1502;

13) Scheer, H. (1995): Solar energy's economic and social benefits, Solar Energy Materials and Solar Cells, Vol. 38, Issues 1-4, pp 555-568;

14) Sibley, M., Sibley, Mar. (2013): Hybrid Green Technologies for Retrofitting Heritage Buildings in North African Medinas: Combining Vernacular and High-tech Solutions for an Innovative Solar Powered Lighting System for Hammam Buildings, Energy Procedia, Vol. 42, pp 718-725;

15) Sozer H., Elnimeiri, M. (2007): Critical factors in reducing the cost of building integrated photovoltaic (BIPV) systems, Architectural Science Review, Vol. 50, pp. 115-121;

16) Wong L.T., Chow W.K. (2001): Solar radiation model, Applied Energy,Vol. 69 (3), pp. 191-224.

Paper sent to revision: 09.03.2014.

Paper ready for publication: 05.06.2014. 